\title{
Bioefficacy of Solvent Fractions of Oreosyce africana and Piper capense against the Malaria Vector, Anopheles arabiensis with High Performance Liquid Chromatographic and Ultraviolet-Visible Spectroscopic Analysis
}

\section{Damtew Bekele ${ }^{1 *}$, Habte Tekie ${ }^{2}$, Zemede Asfaw ${ }^{3}$ and Beyene Petros ${ }^{4}$}

${ }^{1}$ College of Natural and computational Sciences, Department of Biology, Debre Markos University, Debre Markos, Ethiopia

${ }^{2}$ College of Natural Sciences, Department of Zoological Sciences, Addis Ababa University, Addis Ababa, Ethiopia

${ }^{3}$ College of Natural Sciences, Department of Plant Biology and Biodiversity Management, Addis Ababa University, Addis Ababa, Ethiopia

${ }^{4}$ College of Natural Sciences, Department of Microbial, Cellular and Molecular Biology, Addis Ababa University, Addis Ababa, Ethiopia

\begin{abstract}
The efficacy of synthetic inorganic insecticides to control malaria vector mosquitoes is compromised by increased mosquito resistance to insecticides. Furthermore, use of inorganic insecticides raises serious environmental toxicity concerns. The test plants, Oreosyce africana and Piper capense were identified in Ethiopia through ethnobotanical leads obtained on the basis formal and informal field interviews and discussions coupled with literature search for sister species tested elsewhere. The plant powder from these species was extracted using $80 \%$ methanol and the methanol crude extracts of Oreosyce africana and Piper capense were sequentially fractionated with solvents (dichloromethane, ethyl acetate and deionized water). Each fraction was dissolved in dimethyl sulfoxide and deionized water; test concentration prepared and tested for their bioactivity against Anopheles arabiensis adults. The dichloromethane fraction of Oreosyce africana and ethyl acetate fraction of Piper capense had higher adulticidal activities with LC $_{50}$ and $\mathrm{LC}_{90}$ values of 4.27 and $14.12 \mathrm{ppm}$ and 10.72 and $30.59 \mathrm{ppm}$, respectively. Comparison of dichloromethane fraction of Oreosyce africana with ethyl acetate and water fractions showed significant differences at $p<0.05$. And comparison of ethyl acetate fraction of Piper capense with dichloromethane and water fractions showed significant differences at $p<0.05$. Thus, the bioassays with dichloromethane fraction of Oreosyce africana and ethyl acetate fraction of Piper capense exhibited higher adulticidal effect against Anopheles arabiensis than other solvent fractions. Dichloromethane fraction of Oreosyce africana and ethyl acetate fraction of Piper capense were examined under HPLC and UV-Vis for the proximate analysis. These plant products would be ideal alternatives for the control of malaria vector mosquitoes upon fractionation and preparation of suitable delivery packages.
\end{abstract}

Keywords: Oreosyce africana; Piper capense; Anopheles arabiensis; Fractions; Solvent fractions; Adulticidal activity; UV-Vis spectrum; HPLC chromatogram; Ethiopia

Abbreviations: DDT: Dichloro-Diphenyl-Trichloroethane; $\mathrm{MeOH}$ : Methanol; DCM: Dichloromethane; EtOAc: Ethyl acetate; DOF: Dichloromethane Oreosyce Fraction; EOF: Ethyl Acetate Oreosyce Fraction; WOF: Water Oreosyce Fraction; DPF: Dichloromethae Piper Fraction; EPF: Ethyl Acetate Piper Fraction; WPF: Water Piper Fraction; DMSO: Dimethyl Sulfoxide; EPHI: Ethiopian Public Health Institute; ppm: parts per million; WHO: World Health Organization; $\mathrm{LC}_{50}: 50 \%$ Lethal Concentration; $\mathrm{LC}_{90}$ : $90 \%$ Lethal Concentration; HPLC: High Performance Liquid Chromatography; UV-Vis: Ultraviolet-Visible

\section{Introduction}

Malaria still remains one of the most devastating diseases occurring in the world today. The five African countries that include Nigeria, Democratic Republic of Congo, Uganda, Ethiopia, and Tanzania accounted for $50 \%$ of malaria deaths and $47 \%$ of cases [1]. Anopheles arabiensis Patton is widely distributed in Ethiopia and is the major mosquito vector responsible for the transmission of most malaria cases including the occasional seasonal outbreaks and the major periodic cyclical epidemics in the country $[2,3]$.

The ecology of malaria vectors can be influenced by human economic activities. Among these factors are constructions of water reservoirs, canals, irrigations systems, agricultural land reclamations and construction of industrial objects. All these factors leads to considerable change in the earlier existing natural conditions and thus could worsen previous malaria situation in an area. A mosquito's life is critically dependent on water, where the female lays her eggs.
Therefore, agricultural water management needs to a specific attention in Africa. For example, the different aspects of irrigation in agricultural water management such as irrigation efficiency [4-7] and importance of the different studies in various aspects of water sciences $[8,9]$ have been investigated in the previous works, which leads to increasing malaria. To protect the environmental change that affects the malaria situation and ecology of the local vector drainage and environmental engineering technical methods of controlling malaria must be implemented. The purpose of implementing of thus malaria control measure is to prevent the existence of new water-loggings suitable for malaria mosquito breeding in process of planning; construction and exploitation of industrial and agricultural objects, to prevent the construction of borrow areas and reserves close to human settlements.

Historically, the use of synthetic insecticides has been very effective in reducing malaria transmission. However, over time, success has been hampered by mosquito resistance to synthetic insecticides and

${ }^{*}$ Corresponding author: Damtew Bekele, College of Natural and computationa Sciences, Department of Biology, Debre Markos University, Debre Markos, Ethiopia, Tel: 0912-179124, E-mail: damtish99@yahoo.com

Received: July 30, 2016; Accepted: September 20, 2016; Published September 24, 2016

Citation: Bekele D, Tekie H, Asfaw Z, Petros B (2016) Bioefficacy of Solvent Fractions of Oreosyce africana and Piper capense against the Malaria Vector Anopheles arabiensis with High Performance Liquid Chromatographic and Ultraviolet-Visible Spectroscopic Analysis. Biochem Anal Biochem 5: 294. doi:10.4172/2161-1009.1000294

Copyright: @ 2016 Bekele D, et al. This is an open-access article distributed unde the terms of the Creative Commons Attribution License, which permits unrestricted use, distribution, and reproduction in any medium, provided the original author and source are credited. 
this challenged practical mosquito control around the world [10]. According to studies conducted in Ethiopia [11-13], An. arabiensis was resistant to an array of insecticides, including Dichloro-DiphenylTrichloroethane (DDT), permethrin, deltamethrin and malathion.

The bases for the insecticidal effects of the plants are the secondary plant products that are known to be less harmful to non-target organisms. As a result, the use of indigenous plants has increasingly become a major subject of research as they contain an array of bioactive chemical compounds, which would be used to kill or repel mosquitoes at various life stages $[14,15]$. The secondary metabolites which include - anabasine, azadirachtin, d-limonene, nicotine, pyrethrins, quassia and rotenone were among important insecticides widely used [16]. Although several compounds of plant origin have been reported as insecticides, there is still a wide scope for the discovery of more effective plant products [17] particularly in the indigenous flora of lesser studied countries like Ethiopia.

The application of easily degradable botanicals for the control of mosquitoes is recommended [18] because they minimize the accumulation of harmful residues in the environment. Therefore, the alternative control measure is screening of locally available indigenous ethno-medicinal plants as mosquito larvicidal and adulticidal agents that would eventually lead to their usage in plant-based mosquito abatement practices [19]. Although the potency of extracts is less than chemical insecticides, they are safer than the latter [20].

A recent study by Bekele et al. [21] showed that people in Akaki District (east-central Ethiopia) used O. africana, B. nigra and Aloe spp traditionally for mosquito control and for the control of cattle ticks and other arthropod pests. Oreosyce africana Hook. f. (Cucurbitaceae) is a slender climbing herb or trailer growing to $3 \mathrm{~m}$ and its habitat is in wet or moist Pouteria (=Aningeria) adolii-friederici-Syzygium guineense forest margins, grassland and in plantations at altitude between 1650$2000 \mathrm{~m}$ [22]. Piper capense L.f. (Piperaceae) is a small shrub 1-2 m high, possibly sometimes sub-scandent, base semi-woody, much branched above and stems are glabrous. It grows in the understorey of moist montane forest; 1600-2400 m [23].

Bowers et al. [24] reported that the screening of locally available medicinal plants for mosquito control would generate local employment, reduce dependence on expensive imported products and stimulate efforts to enhance public health. The task of developing mosquito control agents from Ethiopian traditional herbal plants with ethnobotanical leads has remained an unaccomplished challenge, though ethnobotanical surveys have catalogued a considerable number of species [25]. There is emergence of resistance to synthetic chemical insecticides which has led to an increase in mosquito population and hence increases in the spread of mosquito-borne diseases like malaria. In addition, there are no reports of potential products derived from plants targeting the adult stages of mosquitoes in an effective way. The results of the present study would be useful in closing on the gap of developing new botanicals from indigenous Ethiopian plant source for possible insecticides. The adulticidal activities of the selected plant species given here against $A n$. arabiensis have not been reported so far. The aim of this study was to investigate the mosquitocidal effects of $O$. africana leaf and $P$. capense fruit for malaria vector control in Ethiopia.

\section{Materials and Methods}

\section{Collection and identification of plant materials}

Leaves of $O$. africana Hook. f (Family: Cucurbitaceae) were collected from Yerer Lencho locality of Akaki district, eastern Ethiopia
(Latitude $08^{\circ} 50.682^{\prime} \mathrm{N}$, longitude $038^{\circ} 56.630^{\prime}$ E, altitude $1936 \mathrm{~m}$ asl) and fruits of $P$. capense L.f. (Piperaceae) were collected from Bada Buna locality of Qarsa district, western Ethiopia (Latitude $07^{\circ} 39.730^{\prime}$ $\mathrm{N}$, longitude $036^{\circ} 53.213^{\prime} \mathrm{E}$, altitude $1779 \mathrm{~m}$ asl). These candidate plant species were collected both through initial literature search followed by field searching in a series of ethnobotanical survey. Voucher specimens and plant materials for extraction and testing were collected during field trips at the sites. Voucher specimens of both species were authenticated by a plant taxonomist in the Department of Plant Biology and Biodiversity Management, Addis Ababa University and deposited at the National Herbarium of Ethiopia found at College of Natural Sciences in Addis Ababa University.

\section{Preparation of plant extracts}

The crude extraction of plant materials and fractionation were done in the Department of Traditional and Modern Medicine of the Ethiopian Public Health Institute (EPHI). Ground leaves of O. africana and fruits of $P$. capense were homogenized with $80 \%$ aqueous methanol (3 liters) three times using Erlenmeyer flasks on orbital shaker (VWR, USA) at room temperature for $72 \mathrm{hrs}$ following standard procedures $[26,27]$. The suspension was then filtered using Whatman no. 1 filter paper (Chatman Int. Ltd, Kent, UK) and the combined filtrate was concentrated using a rotary vacuum evaporator (Staurt ${ }^{\circ} \mathrm{RE} 300, \mathrm{UK}$ ), 22-26 $\mathrm{mm} \mathrm{Hg}$ below $45^{\circ} \mathrm{C}$. The extract thus obtained was concentrated further over water bath (Kottermann, Germany) by evaporating the solvent. The dried extracts were stored in a vial at $-20^{\circ} \mathrm{C}$ in freezing medium until used for fractionation.

\section{Solvent fractionation procedure of Oreosyce africana and Piper capense}

The dried $80 \%$ aqueous methanol crude extracts of $O$. africana and $P$. capense were suspended in deionized water and then partitioned with solvents dichloromethane, ethyl acetate and deionized water using solvent-solvent extraction at room temperature following the methods of Alkofahi et al. [18]. Portions of $60 \mathrm{~g}$ and $65 \mathrm{~g}$ of the $80 \%$ methanol crude extracts of $O$. africana leaf and $P$. capense fruit were suspended in $600 \mathrm{ml}$ deionized water in separatory funnel and, which was extracted three times with $1200 \mathrm{ml}$ dichloromethane (Carlo Erba, France). Extracts of each solvent were filtered using Whatman no.1 filter paper. The mixture was allowed to settle for one day, after which the solvent extract lower layer was slowly drawn off until only the upper layer remained, and partitions were combined and evaporated at $45^{\circ} \mathrm{C}$ to give dichloromethane Oreosyce fraction (DOF) and dichloromethane Piper fraction (DPF). Portions of $61 \mathrm{~g}$ and $60 \mathrm{~g}$ of the crude extracts of $O$. africana and $P$. capense were suspended in $600 \mathrm{ml}$ deionized water in a separatory funnel and each of them was extracted with $1200 \mathrm{ml}$ ethyl acetate (Carlo Erba, France). The ethyl acetate upper layer filtrates were combined and evaporated to give ethyl acetate Oreosyce fraction (EOF) and ethyl acetate Piper fraction (EPF). Finally, each of the water residual layer and the solution were evaporated and lyophilized to dryness to give water Oreosyce fraction (WOF) and water Piper fraction (WPF).

\section{Preparation of yield of fraction and test concentration}

The percentage yield of fractions of $O$. africana and $P$. capense were determined using the formula $\mathrm{W}_{2}-\mathrm{W}_{1} / \mathrm{W}_{0} \times 100$, which is described by Anokwuru et al. [28], where $\mathrm{W}_{2}$ is the weight of the extract and the vial, $\mathrm{W}_{1}$ the weight of the vial alone and $\mathrm{W}_{0}$ the weight of the initial dried sample. Standard stock solutions were prepared at $1 \%$ by dissolving the extracts using the universal solvent dimethyl sulfoxide (DMSO, 
Citation: Bekele D, Tekie H, Asfaw Z, Petros B (2016) Bioefficacy of Solvent Fractions of Oreosyce africana and Piper capense against the Malaria Vector, Anopheles arabiensis with High Performance Liquid Chromatographic and Ultraviolet-Visible Spectroscopic Analysis. Biochem Anal Biochem 5: 294. doi:10.4172/2161-1009.1000294

Carlo Erba, France) at concentration of $0.05 \%$ and diluted in deionized water (deionizer, EasypureII, USA). From this stock solution different concentrations were prepared.

\section{Rearing Anopheles arabiensis Patton from the egg stage}

Anopheles arabiensis, the major malaria vector in Ethiopia, was selected for the testing of adulticidal bioactivities of the test plant extracts. Eggs of An. arabiensis for starting a colony were obtained from the EPHI and reared according to the World Health Organization [29] protocol. The colonies were reared and maintained by using heater and humidifier, which were kept the optimum temperature at about $25^{\circ} \mathrm{C}$ to $27^{\circ} \mathrm{C}$ and relative humidity about $70 \%$ to $80 \%$ and $12 \mathrm{hr}$ light and $12 \mathrm{hr}$ dark photoperiod cycle at the insectary of College of Natural Sciences, Addis Ababa University. Glass petridishes $(10.5 \mathrm{~cm}$ internal diameter) lined with wet filter paper were kept inside the cages for oviposition, then eggs laid on the filter paper were transferred to plastic and enamel trays containing three liters distilled water and allowed to hatch to first instar larvae and kept until they reach the pupae. The larvae were fed on ground Tetramin fish food pellets (Tetra holding Inc., Blacksburg, VA, USA); the feed was applied on alternate days for normal development. Water of the larval culture was changed every third day to avoid decay. The trays containing the larvae were kept in the sun during the early morning hours for keeping the water aerated. After attaining pupae, they were transferred to beakers by disposable pipettes and kept inside the mosquito cages for adult emergence. Food for sustaining Anopheles arabiensis adults in cages $(30 \times 30 \times$ $30 \mathrm{~cm}^{3}$ ) were continuously provided with $10 \%$ sucrose solution with cotton wicks by placing on the top of each cage. The cotton-wool was moistened daily and changed twice weekly. Adult female An. arabiensis were periodically blood-fed on restrained rabbits shaved on the side of their belly for fertile egg production and the feeding was stimulated by darkening the cage. The An. arabiensis reared in the laboratory thus served as the source of adults for the bioassay tests.

\section{Test mosquitoes and experimental design}

Stock solutions were prepared at $1.0 \%$ by dissolving the dried fractions of $O$. africana and $P$. capense in $0.05 \%$ DMSO. The stock solutions were then diluted with deionized water to obtain the different test concentrations $-4,8,16$ and $32 \mathrm{ppm}$ for fractions coded DOF, EOF and WOF and 6, 12, 24 and $48 \mathrm{ppm}$ for fractions coded DPF, EPF, WPF and the positive control ( $0.05 \%$ lambdacyhalothrin). The $0.05 \%$ DMSO in deionized water was used as a negative control. Adult An. arabiensis were exposed to each test concentration together with the positive and negative controls. The bioassay was conducted using WHO test kit consisting of holding and exposure cylindrical plastic tubes both measuring $125 \times 44 \mathrm{~mm}$ following the procedure of WHO [30]. The tests were conducted on uniformly spread impregnated papers $(12 \times$ $15 \mathrm{~cm}^{2}$ ) with respective concentrations of $O$. africana and $P$. capense by dipping the papers. The papers were left to dry at room temperature overnight and then inserted into the WHO tubes for test.

The test mosquito adults were caught from the rearing net cages with the help of a mouth aspirator (12 mm internal diameter), together with $60 \mathrm{~cm}$ of tubing and mouthpiece and released into a plastic holding tube. The WHO bioassay tubes served to expose the mosquito adults to the papers impregnated with fractions and for holding the mosquito adults before and after the exposure period. The bioassays were performed with non-blood-fed mosquitoes of known age (2 to 5 days old post-emergence of An. arabiensis adults) in batches of 20 in each concentration. The mosquitoes were allowed to acclimatize in the holding tube for $1 \mathrm{hr}$ and then exposed to the fractions on the impregnated paper and control for $1 \mathrm{hr}$. At the end of exposure period, the mosquitoes were transferred back to the holding tube and kept for 24 hrs recovery period. A pad of cotton soaked with $10 \%$ sucrose solution was placed on the mesh screen during the holding period of $24 \mathrm{hrs}$. Mortality rates of the mosquitoes were recorded at the end of $24 \mathrm{hrs}$ post exposure period. Three replicates were maintained at a time. This adulticidal activity was evaluated at $25^{\circ} \mathrm{C}$ to $27^{\circ} \mathrm{C}$ and $70 \%$ to $80 \%$ relative humidity. The fraction which exhibited a pronounced adulticidal activity was chosen for further test. There was no need to correct the data with the Abbott's formula [31].

\section{Phytochemical analysis}

Dichloromethane fraction of $O$. africana and ethyl acetate fraction of $P$. capense were subjected to chromatography and spectrophotometer analysis by using high performance liquid chromatography (HPLC) and ultraviolet-visible (UV-Vis) at the traditional medicine and drug research Department of Ethiopian public health institute. The chemicals/reagents were all analytical and HPLC grades. Chromatographic fingerprints of dichloromethane (DCM) fraction of O. africana leaf and EtOAc fraction of $P$. capense fruit were done by injecting into analytical HPLC (WATERS LC-2000 model equipped with Waters 600 pump controller, Waters in-line mobile phase degasser AF, heated column thermostat, and Waters 2484 dual absorbance UV detector operated by millennium 32 software, WATERS, USA). The isocratic elution was done with the mobile phase containing a mixture of water and acetonitrile in $0.1 \%$ trifluoroacetic acid (TFA) $(20: 80, \mathrm{v} / \mathrm{v})$ at a flow rate of $1.00 \mathrm{ml} / \mathrm{min}$. The detection was done at $254 \mathrm{~nm}$. Separation was carried out by low pressure gradient. The chromatographic tests were performed at $20^{\circ} \mathrm{C}$ on a Tracer Extrasil ODS (octadecylsilane), TR416059 $(5 \mu \mathrm{m}, 0.4 \times 25 \mathrm{~cm})$, Teknokroma (Barcelona, Spain), and the injection sample volume was $10 \mu \mathrm{l}$. The mobile phase and the samples were screened with $0.45 \mu \mathrm{m}$ membrane filter. In all data acquisitions, the running time was $30 \mathrm{~min}$.

\section{Isolation and purification of solvent fractions of $O$. africana and $P$. capense Sephadex LH-20 column chromatography}

The portion of EtOAc fraction of $P$. capense was dissolved in chloroform-methanol $(1: 1, \mathrm{v} / \mathrm{v})$ and put into a column of Sephadex LH-20 $(5 \times 74 \mathrm{~cm}$; Fluka, Switzerland $)$ and eluted with a gradient of increasing polarity of $\mathrm{n}$-hexane-chloroform (100:0, 95:5, 90:10, 85:15, $80: 20,75: 25,70: 30,65: 35,60: 40$, and 50:50, v/v). The purified fractions 5 and 6 were combined based on their thin layer chromatography analysis. The combined filtrates were concentrated using a rotary evaporator, and used for UV-Vis measurement.

\section{Preparative thin layer chromatography}

The portion of DCM fraction of $O$. africana was dissolved in chloroform and applied to eight sheets of silica gel $60 \mathrm{~F}_{254}$ TLC plates $(20$ $\times 20 \mathrm{~cm}, 0.25 \mathrm{~mm}$ thickness; Merck, Germany). These were developed in a solvent system of chloroform-methanol (1:15) in a $15 \mathrm{~cm}$ height. Each $1.5 \mathrm{~cm}$ zone was scraped off from its plate and extracted three times with $100 \mathrm{ml}$ of chloroform-methanol (1:9), and each combined filtrates was concentrated in vacuum to dryness. The purified fraction was subjected to UV-Vis measurement.

\section{Ultraviolet/visible light (UV-Vis) spectroscopy measurement}

To detect the UV-Vis absorption spectrum profile of the purified fractions of $O$. africana and $P$. capense, the fractions were measured in the wavelength ranging from $200-800 \mathrm{~nm}$ by using a double beam Ultraviolate-Visible spectrophotometry (UV-Vis) (Shimadzu, Japan) 
Citation: Bekele D, Tekie H, Asfaw Z, Petros B (2016) Bioefficacy of Solvent Fractions of Oreosyce africana and Piper capense against the Malaria Vector, Anopheles arabiensis with High Performance Liquid Chromatographic and Ultraviolet-Visible Spectroscopic Analysis. Biochem Anal Biochem 5: 294. doi:10.4172/2161-1009.1000294

Page 4 of 8

and the characteristic peaks were detected and the peaks values recorded.

\section{Data analysis}

To test variations in An. arabiensis adult mortalities using crude methanol extracts of $O$. africana and $P$. capense, and fractions including DOF, EOF, WOF, DPF, EPF and WPF, the $\mathrm{LC}_{50}$ and $\mathrm{LC}_{90}$ values were determined using probit regression analysis of the statistical package PoloPlus (version 2.0, LeOra Software, Petaluma, California, USA; 2007). The chi-square $\left(\chi^{2}\right)$ probability for goodness of fit test was used to estimate how well the data of each concentration-mortality rate curve fit the assumption of the probit model using statistical package. The 95\% confidence limits of upper confidence limit (UCL) and lower confidence limit (LCL) for the lethal concentration $\left(\mathrm{LC}_{50}\right.$ and $\left.\mathrm{LC}_{90}\right)$ in ppm for adulticidal effects was used to measure variations among the $O$. africana and $P$. capense fractions and lethal concentration ratio confidence limits $(95 \%)$ that did not include 1.0 were considered significant $(\mathrm{p}<0.05)[32]$.

\section{Results}

\section{Yields of $O$. africana and $P$. capense fractions}

The percentage yields of the fractions DOF, EOF and WOF were $24.5 \%, 12.8 \%$, and $15.7 \%$, respectively and the yields of DPF, EPF and WPF were $16.3 \%, 26.9 \%$ and $15.6 \%$ respectively (Table 1 ).

The percentage yields of ethyl acetate and water fractions were lower in O. africana, whereas the percentage yields of water and dichloromethane fractions in $P$. capense were lower as compared with dichloromethane fraction of $O$. africana and ethyl acetate fraction of $P$. capense. The EtOAc fraction yields for the $P$. capense was the highest

\begin{tabular}{|c|c|c|c|}
\hline Plant species & Plant part (g) & Solvent used & Percent yield of fraction \\
\hline $\begin{array}{c}\text { Oreosyce } \\
\text { africana }\end{array}$ & Leaves (905) & Dichloromethane & $24.5 \% \mathrm{DOF}^{\mathrm{a}}$ \\
\hline & & Ethyl acetate & $12.8 \% \mathrm{EOF}^{\mathrm{b}}$ \\
\hline Piper capense & Fruits (815) & Wichloromethane & $15.7 \% \mathrm{WOF}^{\mathrm{c}}$ \\
\hline & & Ethyl acetate & $16.3 \% \mathrm{DPF}^{\mathrm{d}}$ \\
\hline & & Water & $15.6 \% \mathrm{WPF}^{\mathrm{e}}$ \\
\hline
\end{tabular}

Note: a Dichloromethane Oreosyce fraction, ${ }^{b}$ Ethyl acetate Oreosyce fraction, ${ }^{c}$ Water Oreosyce fraction, ${ }^{\mathrm{d}}$ Dichloromethane Piper fraction, ${ }^{\mathrm{e}}$ Ethyl acetate Piper fraction, ${ }^{f}$ Water Piper fraction.

Table 1: Percentage yields of Oreosyce africana and Piper capense fractions obtained using solvents of different polarities from their $80 \%$ methanolic crude extracts.

\begin{tabular}{|c|c|c|c|c|c|}
\hline $\begin{array}{l}\text { Extract } \\
\text { Tested }^{*}\end{array}$ & $\begin{array}{c}\mathrm{LC}_{50} \mathrm{ppm}(95 \% \\
\mathrm{CL})\end{array}$ & $\begin{array}{c}\mathrm{LC}_{90} \\
\mathrm{ppm}(\mathrm{PL})\end{array}$ & Slope \pm SE & $X^{2}(p)$ & $\begin{array}{l}\mathrm{LC}_{50} \text { ratio } \\
(95 \% \mathrm{CL})\end{array}$ \\
\hline DOF & $\begin{array}{l}4.267(1.325- \\
6.451)\end{array}$ & $\begin{array}{c}14.123(9.268- \\
49.248)\end{array}$ & $\begin{array}{l}2.466 \pm \\
0.289\end{array}$ & $\begin{array}{l}3.127 \\
(0.47)^{\mathrm{a}}\end{array}$ & $\begin{array}{c}3.051(2.339- \\
3.980)^{\mathrm{b}}\end{array}$ \\
\hline EOF & $\begin{array}{c}14.562(13.720- \\
25.292)\end{array}$ & $\begin{array}{c}82.57(69.094- \\
98.728)\end{array}$ & $\begin{array}{l}1.701 \pm \\
0.206\end{array}$ & $\begin{array}{l}5.086 \\
(0.53)^{\mathrm{a}}\end{array}$ & $\begin{array}{c}0.894(0.692- \\
1.154)\end{array}$ \\
\hline WOF & $\begin{array}{c}16.973(13.456- \\
17.209)\end{array}$ & $\begin{array}{c}117.877(88.475- \\
157.372)\end{array}$ & $\begin{array}{l}1.523 \pm \\
0.204\end{array}$ & $\begin{array}{c}6.65 \\
(0.48)^{\mathrm{a}}\end{array}$ & $\begin{array}{c}0.767(0.580- \\
1.1014\end{array}$ \\
\hline $\begin{array}{l}\text { Negative } \\
\text { control }^{* *}\end{array}$ & 0.0 & 0.0 & 0.0 & 0.0 & 0.0 \\
\hline
\end{tabular}

*The codes used for the fractions was the same as in Table $1,{ }^{* *}$ DMSO $(0.05 \%)$ in deionized water, a Good fit of the data to the probit model ( $p>0.05),{ }^{b} \mathrm{LC}_{50}$ ratio significant at $p<0.05 ; 95 \%$ confidence interval did not comprise the value 1.0 .

Table 2: Evaluation of the effect of solvent fractions of Oreosyce africana agains An. arabiensis adults after $24 \mathrm{hrs}$ post exposure on impregnated papers in WHO test tubes ( $n=60$ in each test).

\begin{tabular}{|c|c|c|c|c|c|}
\hline $\begin{array}{l}\text { Extracts } \\
\text { tested }\end{array}$ & $\begin{array}{l}\mathrm{LC}_{50} \text { ppm } \\
(95 \% \mathrm{CL})\end{array}$ & $\underset{\text { CL) }}{L^{2} C_{90}}$ ppm $(95 \%$ & Slope \pm SE & $X^{2}(p)$ & $\begin{array}{l}\text { LC }_{50} \text { ratio } \\
(95 \% \mathrm{CL})\end{array}$ \\
\hline DPF & $\begin{array}{c}27.661(22.75- \\
35.504)\end{array}$ & $\begin{array}{r}173.493 \\
(107.212- \\
380.843)\end{array}$ & $1.607 \pm 0.207$ & $\begin{array}{l}1.815 \\
(0.46)^{\mathrm{a}}\end{array}$ & $\begin{array}{l}0.923 \\
(0.695- \\
1.224)\end{array}$ \\
\hline EPF & $\begin{array}{c}10.715(9.349- \\
12.100)\end{array}$ & $\begin{array}{c}30.591(25.796- \\
38.413)\end{array}$ & $2.813 \pm 0.261$ & $\begin{array}{c}0.569 \\
(0.56)^{\mathrm{a}}\end{array}$ & $\begin{array}{l}2.382 \\
(1.908- \\
2.972)^{\mathrm{b}}\end{array}$ \\
\hline WPF & $\begin{array}{l}28.196 \\
(21.534- \\
36.876)\end{array}$ & $\begin{array}{l}150.614 \\
(131.959- \\
208.212)\end{array}$ & $1.761 \pm 0.213$ & $\begin{array}{l}0.988 \\
(0.45)^{a}\end{array}$ & $\begin{array}{c}0.905 \\
(0.692- \\
1.185\end{array}$ \\
\hline $\begin{array}{l}\text { Negative } \\
\text { control** }^{* *}\end{array}$ & 0.0 & 0.0 & 0.0 & 0.0 & 0.0 \\
\hline \multicolumn{6}{|c|}{$\begin{array}{l}{ }^{*} \text { The codes used for the fractions were the same as in Table } 1,{ }^{* *} \text { DMSO } \\
(0.05 \%) \text { in deionized water, a Good fit of the data to the probit model }(p>0.05) \text {, } \\
{ }^{\circ} \mathrm{LC}_{50} \text { ratio significant }(p<0.05), 95 \% \text { confidence interval did not comprise the } \\
\text { value } 1.0 \text {. }\end{array}$} \\
\hline
\end{tabular}

Table 3: Evaluation of the effect of solvent fractions of $P$. capense against $A n$. arabiensis after $24 \mathrm{hrs}$ post exposure on impregnated papers in WHO test tubes $(n=60$ in each test)

followed by DCM fraction yields for O. africana (Table 1). These fractions were subjected to adulticidal test against An. arabiensis adults.

\section{Adulticidal activity}

Quantitative estimation in all the solvent fractions of O. africana was carried out to determine the lethal concentrations $\left(\mathrm{LC}_{50}\right.$ and $\mathrm{LC}_{90}$ ) of a particular fraction (Table 2). All chi-square values were not significant $(\mathrm{p}=0.05)$ in goodness of fit test on the probit model, indicating a good fit of regression line (Table 2). A comparison of the various solvent fractions of $O$. africana in regard to $\mathrm{LC}_{50}$ and $\mathrm{LC}_{90}$ values showed the dichloromethane fraction with 4.267 and 14.123 ppm, respectively to be significantly different at $\mathrm{p}<0.05$ and it was the most potent adulticidal activity against $A n$. arabienis adults than the solvent fractions of ethyl acetate and water (Table 2).

With regard to $P$. capense fractions, all chi-square values were not significant $(\mathrm{p}=0.05)$ in goodness of fit test on the probit model, indicating a good fit of regression line (Table 3 ). The ethyl acetate fraction of $P$. capense with $\mathrm{LC}_{50}$ at 10.715 and $\mathrm{LC}_{90}$ at $30.591 \mathrm{ppm}$ showed potent adulticidal effect against adults of $A n$. arabiensis and it differed significantly at $\mathrm{p}<0.05$ than its dichloromethane and water fractions (Table 3).

\section{Chromatographic analysis}

The qualitative HPLC fingerprint profile of the DCM fraction of $O$. africana and EtOAc fraction of $P$. capense was selected at a wavelength of $254 \mathrm{~nm}$ due to the sharpness of the peaks and proper baseline. The HPLC profile of DCM fraction of $O$. africana displayed two prominent peaks with $58.98 \%$ and $30.73 \%$ area under the peak at retention times of 12.60 and $5.04 \mathrm{~min}$, respectively and some moderate peaks were also observed at retention times of 13.26 and 5.32 min (Figure 1). The HPLC chromatographic profile of EtOAc fraction of $P$. capense is shown in Figure 2. The three major first, third and tenth peaks with area percentage of $15.68,14.99$, and 14.82 appeared at the retention times of $8.37,3.54$, and $3.08 \mathrm{~min}$, respectively.

\section{Spectrophotometric analysis}

The UV-Vis measurement of the dichloromethane fraction of $O$. africana and ethyl acetate fraction of $P$. capense was taken at the 200 to $800 \mathrm{~nm}$ wavelength due to the sharpness of the peaks and proper baseline. The UV-Vis measurement of dichloromethane fraction of $O$. africana showed the maxima peaks at $663.00,605.00,534.00,410.00$ and $368 \mathrm{~nm}$ at absorbance of $0.096,0.025,0.035,0.380$ and 0.332 , 
Citation: Bekele D, Tekie H, Asfaw Z, Petros B (2016) Bioefficacy of Solvent Fractions of Oreosyce africana and Piper capense against the Malaria Vector, Anopheles arabiensis with High Performance Liquid Chromatographic and Ultraviolet-Visible Spectroscopic Analysis. Biochem Anal Biochem 5: 294. doi:10.4172/2161-1009.1000294

Page 5 of 8

respectively (Figure 3) with low intensity region of $382.00 \mathrm{~nm}$ and $358.00 \mathrm{~nm}$ at absorbance of 0.317 and 0.330 , respectively. The UV-Vis measurement of ethyl acetate fraction of $P$. capense showed the maxima peaks at 268.00 and $212.00 \mathrm{~nm}$ with low intensity region of $247.00 \mathrm{~nm}$ at absorbance of $1.289,3.686$ and 1.108 , respectively (Figure 4).

\section{Discussion}

The leads supplied by local traditional medicine practitioners and knowledgeable elders from the geographical areas where the plants were collected were the most critical guides in the study. The approach helped to identify the plants whose extracts possessed antiAn. arabiensis potency. The rationale for considering plant materials for anti-mosquito effects was because plants are rich sources of bioactive secondary metabolites and offer an advantage over synthetic insecticides as their extracts are less toxic, less prone to development of resistance, and easily biodegradable thereby reducing the possible accumulation of toxic residues in the environment [33]. The plant fractions that showed activities in the study are expected to offer advantages as insecticides over synthetic products.

Crude methanol extracts of $O$. africana and $P$. capense were further extracted with a less polar organic solvent, ethyl acetate and dichloromethane and a polar solvent (water) to give six extracts. Among the three fractions isolated from O. africana, dichloromethane fraction showed the maximum yield, and of the three fractions isolated from P. capense, ethyl acetate fraction showed the maximum yield. The results of the percentage yield suggested that dichloromethane was a better solvent for the fractionation of $O$. africana, while ethyl acetate was a better solvent for the fractionation of $P$. capense.

Therefore, it is to be expected that since different phytoconstituents dissolve in specific solvents [34], the DCM fraction of O. africana and ethyl acetate (EtOAc) fraction of $P$. capense would contain constituents with demonstrated adulticidal activity in the present study. Furthermore, since the yields of the active component, in addition to its bioactivity, would determine the suitability of plant extracts for mosquito control.

The rationale for extract fractionation by using solvents with different polarity gradients to water, the most polar (polar index, $\mathrm{P}=9.0)$, ethyl acetate $(\mathrm{P}=4.4)$, and dichloromethane $(\mathrm{P}=3.1)$ was because different organic solvents show difference in dissolving the bioactive components present in the plant materials. In this connection, Shaalan et al. [35] reported that the different solvents can significantly affect the potency of extracted plant compounds. This study is in line with

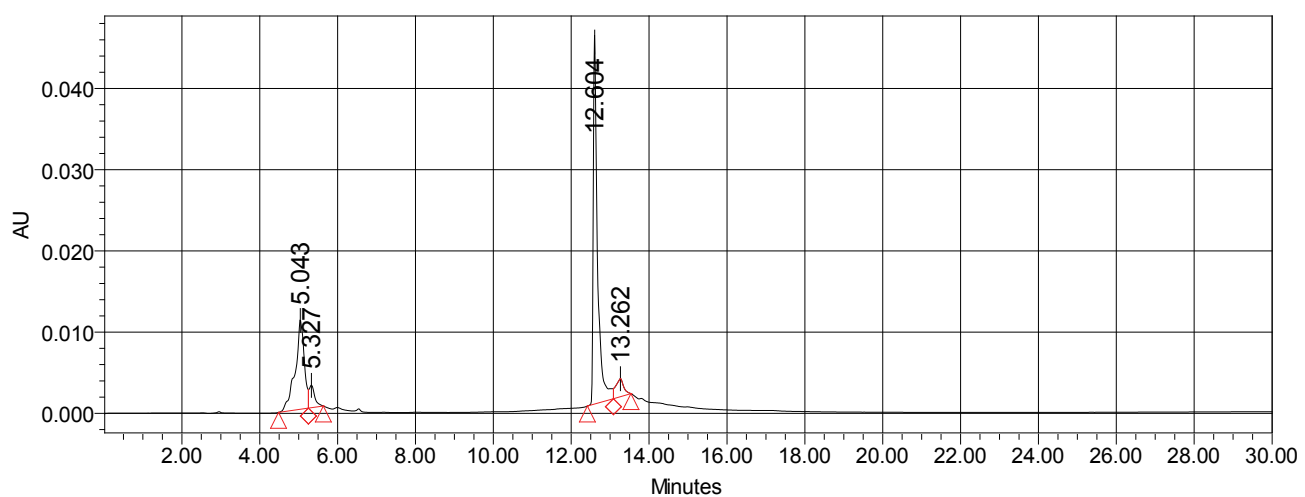

Figure 1: HPLC Chromatogram of DCM fraction of $O$. africana leaf. (Elution was done with water-acetonitrile in $0.1 \%$ TFA (20:80) at a flow rate of $1.00 \mathrm{ml} / \mathrm{min}$; detection, absorbance at $254 \mathrm{~nm}$ )

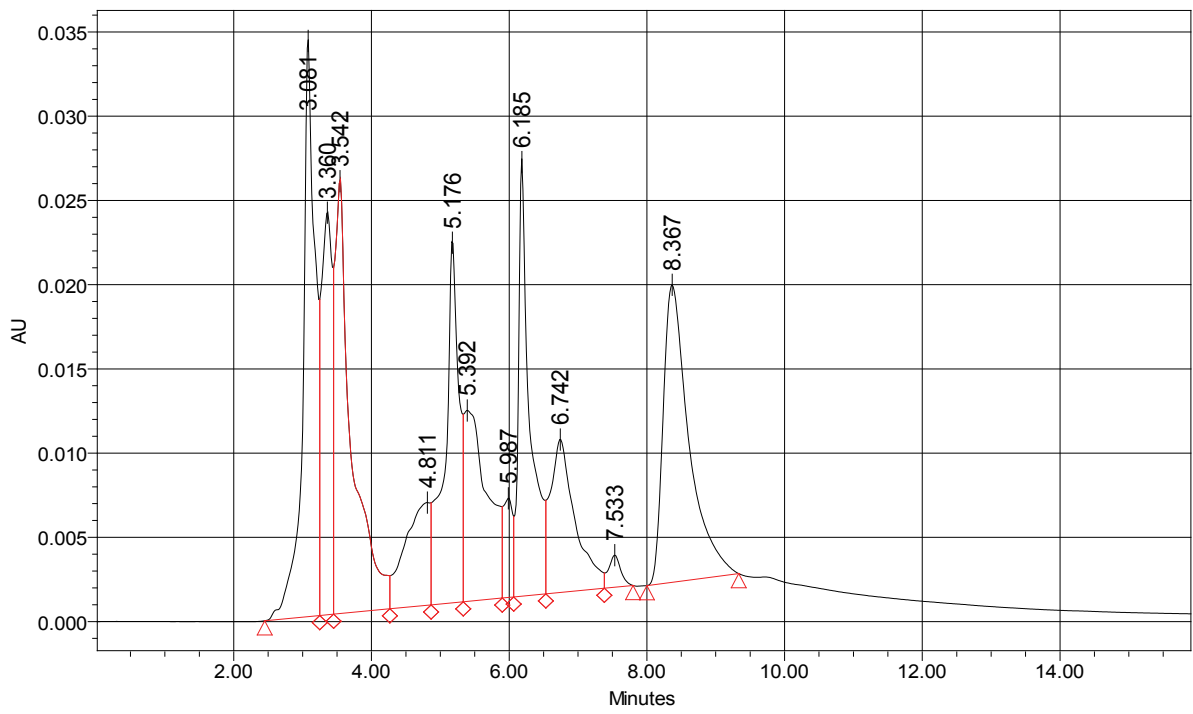

Figure 2: HPLC Chromatogram of ethyl acetate fraction of $P$. capense fruit. (Elution was done with water-acetonitrile in $0.1 \%$ TFA (20:80) at a flow rate of $1.00 \mathrm{ml} / \mathrm{min}$; detection, absorbance at $254 \mathrm{~nm}$. HPLC was done as described in materials and methods). 
Citation: Bekele D, Tekie H, Asfaw Z, Petros B (2016) Bioefficacy of Solvent Fractions of Oreosyce africana and Piper capense against the Malaria Vector, Anopheles arabiensis with High Performance Liquid Chromatographic and Ultraviolet-Visible Spectroscopic Analysis. Biochem Anal Biochem 5: 294. doi:10.4172/2161-1009.1000294

Page 6 of 8

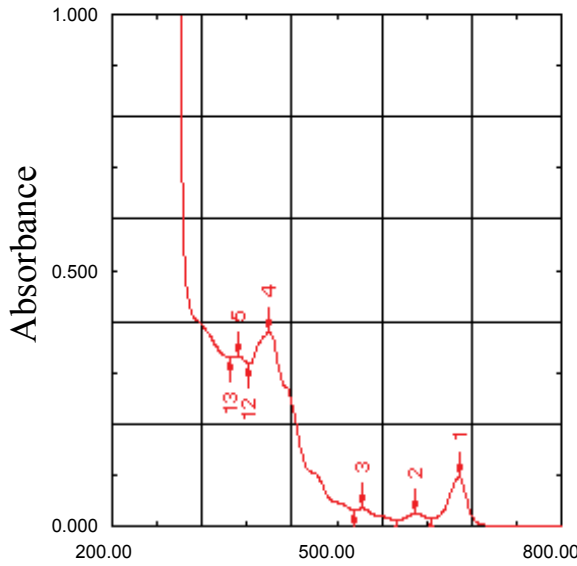

Figure 3: UV-Vis spectrum of purified fraction of $O$. africana leaf.

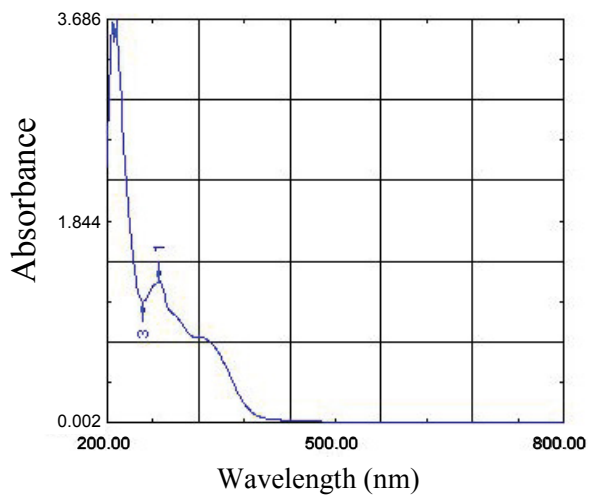

Figure 4: UV-Vis spectrum of purified fraction of $P$. capense fruit.

the observation of Aivazi and Vijayan [36] in oak gall extracts and Mulla and Su [37] in neem plant extracts, who report that a converse relationship between extract effectiveness and solvent polarity where the efficacy increases with decreasing polarity.

Hidayatulfathi et al. [38] also indicates that the bioactive components from Acorus calamus (Acoraceae) responsible for the lethal effect on the adults were extracted in greater measures with certain solvents. However, this is not consistent due to differences between the characteristics of active chemicals among plants. From this, it is clear that the bioactive components responsible for the lethal effect on mosquitoes were extracted in greater measures with certain solvents only and not with all.

The high mosquitocidal activity of DCM fraction of $O$. africana is consistent with the report of Broussalis et al. [39] for the dichloromethane extracts of Tagetes erecta L. (Fabaceae/Compositae) which showed a significant pesticidal activity against Sitophilus oryzae. In the current study, the higher activity of DCM fraction of $O$. africana and EtOAc fraction of $P$. capense may be due to the presence of bioactive components against adult stage of An. arabiensis. In line with a study by Asghari et al. [40], DCM is a semi-polar solvent that had the ability to dissolve polar and non-polar compounds in the extract of $O$. africana. This indicates that the bioactive components in this plant had adulticidal properties against An. arabiensis and were better soluble in DCM than in other solvents.

The reason for the higher adulticidal activity of DCM fraction may be due to presence of both polar and non-polar active compounds. The solvent-specific nature of extraction of bioactive constituents was also shown by the ethyl acetate fraction of $P$. capense that also had a superior adulticidal effect on adult mosquitoes compared to the aqueous fraction. The finding that $O$. africana and $P$. capense aqueous methanol crude extract fractions against An. arabiensis adult mosquito effects were solvent-specific and each had different efficacies; and shows the difference in the nature of the insecticidal chemical constituents in the two plants. Furthermore, the adulticide activities of the plant fractions tested against An. arabiensis were concentration dependent.

Among the three fractions isolated from $O$. africana, dichloromethane fraction showed the most potent adulticide $\left(\mathrm{LC}_{50}\right.$ at $4.35 \mathrm{ppm}$ ), while the least effective one was the water fraction $\left(\mathrm{LC}_{50}\right.$ at $55.14 \mathrm{ppm}$ ). This indicates that constituents active against adult mosquitoes were eluted in the dichloromethane fraction. The finding in the present study that dichloromethane partitioned of $O$. africana had superior toxicity against adults $A n$. arabiensis is supported by the report of Joseph et al. [41] who show DCM extracts of the plant Neorautanenia mitis, to have the highest ( $\mathrm{LC}_{50} 3.05 \mathrm{ppm}$ ) anti-adult $A n$. gambiae activity. The high potency of the DCM fraction of $O$. africana and EtOAc fraction of $P$. capense against An. arabiensis adults at low concentrations could reasonably be attributed to the active constituent of secondary metabolites with mosquitocidal activity.

Fractionation of the extracts allowed to minimize the number of compounds in each solvent extract tested for mosquitocidal effect. As the purpose of fractionating crude extracts for bioactivity is to extract as many potentially active constituents as possible, the observed weak to very strong adulticidal effects of the different solvent fractions was an indication that the plant extracts consisted of different phytochemicals with varying adulticidal potencies. Similarly, a study by Uthayarasa et al. [42] report that sequential extraction directed to minimize compounds in plant extract thereby the anatagonistic effect can be reduced and also the isolation and purification can easily be undertaken to find out natural mosquitocides from plant origin.

Furthermore, such variation in the bioactivities of different solvent fractions of crude extracts that screened with ethyl acetate, n-butyl alcohol and water fractions of alcoholic extracts of leaves and stems of Vanilla fragrans against $C x$. pipiens larvae found that both n-butyl alcohol and ethyl acetate fractions were active in bioassays, while the water fraction appeared to contain no substances that inhibited larval growth [43]. This shows that the activity of some crude extracts may be attributed to the complex mixture of bioactive compounds

On the other hand, the demonstration in the present study that the activity of DCM fraction of O. africana was much higher as a mosquito adulticide compared to the ethyl acetate and water fractions, shows that the potency of the active constituents in the crude extracts may also be masked by other, less active or completely inactive, minor constituents. This was further evident from $P$. capense extracts whereby the ethyl acetate fraction was more potent as a mosquito adulticide as compared with its crude methanol extract and the dichloromethane and water fractions. This is consistent with a previous report that showed mortality rates of mosquitoes declined with increasing polarity of the solvent. These authors showed that water extracts of Zanthoxylum heitzii (Rutaceae) produced the lowest adult mortalities whereas its ethyl acetate and hexane extracts produced higher mortalities against Anopheles gambiae [44].

The peaks obtained in UV-VIS spectrum of $O$. africana fraction has absorption bands at 368.0, 410.0, 534.0, 605.0 and $663.0 \mathrm{~nm}$, and $P$. capense fraction has absorption bands at 212.0 and $268.0 \mathrm{~nm}$. The Flavonoids and Terpinoids spectra typically consist of two absorption 
Citation: Bekele D, Tekie H, Asfaw Z, Petros B (2016) Bioefficacy of Solvent Fractions of Oreosyce africana and Piper capense against the Malaria Vector, Anopheles arabiensis with High Performance Liquid Chromatographic and Ultraviolet-Visible Spectroscopic Analysis. Biochem Anal Biochem 5: 294. doi:10.4172/2161-1009.1000294

maxima, the first in the ranges $230-290 \mathrm{~nm}$ (band I) and the second in the ranges 400-500 $\mathrm{nm}$ (band II). The chlorophyll spectra typically consist of two absorption maxima in the ranges $600-700 \mathrm{~nm}$. The precise position and relative intensities of these maxima give valuable information on the nature of the Flavonoids $[45,46]$.

\section{Conclusion}

Plant-derived natural insecticides could be useful as an alternative for synthetic insecticides. In the present study, O. africana and $P$. capense are easily available, accessible and affordable. Therefore, in addition to encouraging the continued uses of these traditional medicinal plants among the local residents, the use of these plant extracts should be promoted in order to reduce the human-vector contact as well as vector-borne diseases. Further studies on the toxicity test of dichloromethane fraction of O. africana and ethyl acetate fraction of $P$. capense against non-target organisms may provide futuristic lead products for field application for routine mosquito control.

\section{Acknowledgement}

The authors would like to thank the Department of Microbial, Cellular and Molecular Biology and Thematic Research of Malaria and other Parasitic Diseases for their financial support. We are grateful to Dr. Birkinesh Ameneshewa, Integrated Vector Management Protection of Human Environment at WHO Regional Office for Africa, for providing the WHO test kit for the bioassay test work. We also thank Dr. Asfaw Debella, Mr. Yehualashet Belete and Mr. Fitsum Tesfaye, Ethiopian Public Health Institute, for the assistance with phytochemical analysis, and mosquito rearing.

\section{References}

1. World Health Organization (2010) World Health Organization global malaria program: World malaria report, Geneva.

2. Abose T, Yeebiyo Y, Olana D, Alamirew D, Beyene Y, et al. (1998) Reorientation and definition of the role of malaria vector control in Ethiopia. WHO/MAL.

3. Ministry of Health (1999) Guidelines for malaria epidemic prevention and control in Ethiopia, Ministry of Health, Berhanena Selam Press, Addis Ababa.

4. Valipour M (2012) Hydro-module determination for Vanaei Village in Eslam Abad Gharb, Iran. ARPN J Agr Biol Sci 7: 968-976.

5. Valipour M (2013) Increasing irrigation efficiency by management strategies: cutback and surge irrigation. ARPN J Agr Biol Sci 8: 35-43.

6. Valipour M (2013) Use of surface water supply index to assessing of water resources management in Colorado and Oregon, USA. Adv Agr Sci Eng Res 3: 631-640.

7. Valipour M (2013) Evolution of irrigation-equipped areas as share of cultivated areas. Irrigat Drainage Sys Eng 2: e114.

8. Valipour M (2014) Handbook of drainage engineering problems. Foster City (CA): Omics Group eBooks.

9. Valipour M (2015) Handbook of environmental engineering problems. Foster City (CA): Omics Group eBooks.

10. Brown AWA (1986) Insecticide resistance in mosquitoes: a pragmatic review. $J$ Am Mosq Control Assoc 2: 123-140.

11. Balkew M, Gebre-Michael T, Hailu A (2003) Insecticide susceptibility level of Anopheles arabiensis in two agro-development localities in Eastern Ethiopia. Parasitologia 45: 1-3.

12. Abate A, Hadis M (2011) Susceptibility of Anopheles gambiae s.l. to DDT, malathion, permethrin and deltamethrin in Ethiopia. Trop Med Int HIth 16: 486491.

13. Yewhalaw D, Wassie F, Steurbaut W, Spanoghe P, Bortel WV, et al. (2011) Multiple insecticide resistance: an impediment to insecticide-based malaria vector control programe. Plos One 6: 1-7.

14. Ahmed SGM, Hylin JW, Mitchell WC, Litsinger JA (1984) Investigating the feasibility of using botanical materials for pest control under traditional farming system. Proceedings of the second International Joint Conference on a suggested Neem approach.
15. Karunamoorthi K, Mulelam A, Wassie F (2008) Laboratory evaluation of traditional insect/mosquito repellent plants against Anopheles arabiensis, the predominant malaria vector in Ethiopia. Parasitol Res103: 529-534.

16. Wood A (2003) Compendium of pesticide common names: Insecticides.

17. Saxena SC, Yadav RS (1986) A preliminary laboratory evaluation of an extract of leaves of Delonix regia Raf. as a disruptor of insect growth and development. Trop Pest Manag 32: 58-59.

18. Alkofahi A, Rupprecht JK, Anderson JE, Mclaughlin JL, Mikolajczak KL, et al (1989) Search for new pesticides from higher plants. In: insecticides of plant origin. ACS Symp Ser 3: 25-43

19. Karunamoorthi K, Ilango K (2010) Larvicidal activity of Cymbopogon citratus (DC) Stapf. and Croton macrostachyus Del. against Anopheles arabiensis Patton, a potent malaria vector. Eur Rev Med and Pharmacol Sci 14: 57-62.

20. Mann R, Kaufman P (2012) Natural product pesticides: Their development delivery and use against insect vectors. Mini-Reviews Organic Chem 9 : 185-202.

21. Bekele D, Asfaw Z, Petros B, Tekie H (2012) Ethnobotanical study of plants used for protection against insect bite and for the treatment of livestock health problems in rural areas of Akaki District, Eastern Shewa, Ethiopia. Topclass $J$ Herbal Med 1: 40-52.

22. Jeffrey C (1995) Cucurbitaceae. In: Edwards S, Tadesse M, Hedberg I (eds) Flora of Ethiopia and Eritrea, Vol. 2, Part 2, Canellaceae to Euphorbiaceae. The National Herbarium, Addis Ababa, Ethiopia and the Department of Systematic Botany, Uppsala, Sweden.

23. Gilbert MG (2000) Piperaceae. In: Edwards S, Tadesse M, Demissew S, Hedberg I (eds). Flora of Ethiopia and Eritrea Vol. 2, Part I, Mangoliaceae to Flacourtiaceae. The National Herbarium, Addis Ababa, Ethiopia and the Department of Systematic Botany, Uppsala, Sweden.

24. Bowers WS, Sener B, Evans PH, Bingol F, Erdogani I (1995) Activity of Turkish medicinal plants against mosquitoes Aedes aegypti and Anopheles gambiae. Insect Sci App 16: 339-342.

25. Meragiaw M, Asfaw Z (2014) Review of antimalarial, pesticidal and repellen plants in the Ethiopian traditional herbal medicine. Research and Reviews: J Herbal Sci 3: 21-45.

26. Phrompittayarat W, Putalun W, Tanaka H, Jetiyanon K, Wittaya-areekul S, et al. (2007) Comparison of various extraction methods of Bacopa monnier. Naresuan Univ J 15: 29-34.

27. Sasidharan S, Darah I, Jain K (2008) In vivo and in vitro toxicity study of Gracilaria changii. Pharm Biol 46: 413-417.

28. Anokwuru CP, Anyasor GN, Ajibaye O, Fakoya O, Okebugwu P (2011) Effect of extraction solvents on phenolic, flavonoid and antioxidant activities of three Nigerian medicinal plants. Nature Sci 9: 53-61.

29. World Health Organization (1975) Manual on practical entomology in malaria part II, the WHO division of malaria and other parasitic diseases. World Health Organization, offset publication No.13, Geneva.

30. World Health Organization (2009) Guidelines for efficacy testing of insecticides for indoor and outdoor ground-applied space spray applications for control of neglected tropical diseases: WHO pesticide evaluation scheme. WHO/HTM/ NTD/WHOPES/2009, Geneva.

31. Abott WS (1925) A method of computing the effectiveness of an inseciticide. Econ Entomol 18: 265-266.

32. Robertson JL, Russell RM, Preisler HK, Savin NE (2007) Bioassays with arthropods. (2ndedn), Taylor \& Frances CRC Press.

33. Prabakar K, Jebanesan A (2004) Larvicidal efficacy of some Cucurbitaceous plant leaf extracts against Culex quinquefasciatus Say. Bioresour Technol 95 113-114.

34. Sukumar K, Perich MJ, Boobar LR (1991) Botanical derivative in mosquito control: a review. J Am Mosq Control Assoc 7: 210-237.

35. Shaalan EA, Canyon D, Younes MWF, Abdel-Wahab H, Mansour A (2005) A review of botanical phytochemicals with mosquitocidal potential. Environ Int 31: 1149-1166

36. Aivazi AA, Vijayan VA (2009) Larvicidal activity of oak Quercus infectoria oliv. (Fagaceae) gall extracts against Anopheles stephensi Liston. Parasitol Res 104: $1289-1293$. 
Citation: Bekele D, Tekie H, Asfaw Z, Petros B (2016) Bioefficacy of Solvent Fractions of Oreosyce africana and Piper capense against the Malaria Vector, Anopheles arabiensis with High Performance Liquid Chromatographic and Ultraviolet-Visible Spectroscopic Analysis. Biochem Anal Biochem 5: 294. doi:10.4172/2161-1009.1000294

Page 8 of 8

37. Mulla MS, Su T (1999) Activity and biological effects of neem products against arthropods of medical and veterinary importance. J Am Mosq Control Assoc 15: 133-152.

38. Hidayatulfathi O, Sallehuddin S, Ibrahim J (2004) Adulticidal activity of some Malaysian plant extracts against Aedes aegypti L. Trop Biomed 21: 61-67.

39. Broussalis AM, Ferraro GE, Martino VS, Pinzo'n R, Coussio JD, et al. (1999) Argentine plants as potential source of insecticidal compounds. J Ethnopharmacol 67: 219-223.

40. Asghari G, Nouralliahi H, Havaie SA, Issa L (2006) Antimicrobial activity of Otostegia persica Boiss extracts. Res Pharm Sci 1: 53-58.

41. Joseph CC, Ndoile MM, Malima RC, Nkunya MHH (2004) Larvicidal and mosquitocidal extracts, a coumarin, isoflavonoids and pterocarpans from Neorautanenia mitis. Trans R Soc Trop Med Hyg 98: 451-455.
42. Uthyarasa K, Surendran SN, Pathmanathan MK, Jeyadevan JP (2010) Larvicidal efficacy of crude extracts of Emblica officinalis and Eucalyptus citriodora against Aedes aegypti L. Int J Pharm Biol Arch 1: 467-472.

43. Sun R, Sacalis JN, Chin C, Still CC (2001) Bioactive aromatic compounds from leaves and stems of Vanilla fragrans. J Agric Food Chem 49: 5161-5164.

44. Overgaard $\mathrm{HJ}$, Sirisopa $\mathrm{P}$, Mikolo $\mathrm{B}$, Malterud $\mathrm{KE}$, Wangensteen $\mathrm{H}$, et al. (2014) Insecticidal activities of bark, leaf and seed extracts of Zanthoxylum heitzii against the African malaria vector Anopheles gambiae. Molecules 19 21276-21290.

45. Saxena M, Saxena J (2012) Evaluation of phytoconstituents of Acorus calamus by FTIR and UV-VIS spectroscopic analysis. Intl J Biol Pharm Res 2012: 498-501.

46. Sahu N, Saxena J (2013) Phyto-chemical analysis of Bougainvillea glabra choisy by FTIR and UV-VIS spectroscopic analysis. Int J Pharm Sci Rev Res $n^{\circ} 33$ 21: 196-198. 